STO-3G orbital energies for the four highest occupied MO's of 10 (Figure 2) are within $6.4 \mathrm{eV}$, whereas the energy gap between the HOMO and the three LUMO's (Figure 3) is 10.3-13.0 eV. For carbonium ions, the energy of the empty p orbital is close to that of occupied orbitals so homoaromaticity is permitted. It might be questioned whether minimal basis set calculations underestimate mixings between occupied and virtual orbitals. Actually, they tend to overestimate such charge-transfer interactions. ${ }^{28}$

At this point, it may be asked what is controlling the relative acidities of 1-5? One must be cautious in attempting to explain differences of only a few kilocalories/mole in MO terms. With this in mind some proposals may be considered. The most obvious possibility is inductive effects. With increasing unsaturation the $\sigma$ frameworks of the ions become more electronegative and better able to accommodate the negative charge. The effect is manifested in a general lowering of $\mathrm{MO}$ energies for the more unsaturated species. For example, the energy of the $\chi_{2}$ HOMO decreases by $0.15 \mathrm{eV}$ in going from 8 to 10 according to the STO-3G results. It may also be noted that the MO coefficients show that $\chi_{2}$ mixes slightly with the $\sigma_{\mathrm{CC}}$ and $\sigma_{\mathrm{CC}}{ }^{*}$ bond orbitals for the $\mathrm{C} 1 \mathrm{C} 7, \mathrm{C} 1 \mathrm{C} 8$, $\mathrm{C} 5 \mathrm{C} 6$, and $\mathrm{C} 5 \mathrm{C} 9$ bonds. This is indicated by the small contributions to the $\chi_{2} \mathrm{MO}$ at $\mathrm{C} 6-\mathrm{C} 9$ in Figure 2. As the bridges become unsaturated, the $\sigma_{\mathrm{CC}}$ and $\sigma_{\mathrm{CC}} *$ orbitals are lowered in energy which makes the mixings with $\chi_{2}$ less energetically unfavorable.

Finally, the preference for $C_{20}$ symmetry in $\mathbf{1 0}$ is easily understood from the orbital analyses. Tilting the allylic fragment toward an ethylenic bridge increases the four-electron repulsion between $\pi_{-}$and $\chi_{1}$ much faster than it increases stabilizing in-

(28) Umeyama, H.; Morokuma, K. J. Am. Chem. Soc. 1977, 99, 1316. teractions between occupied and unoccupied orbitals. This effect has been corroborated by both MINDO/3 and STO-3G calculations.

\section{Conclusion}

An important finding in the present study is that reasonable relative acidities for alkenes can be obtained from minimal basis set ab initio calculations, particularly for structurally similar molecules. Furthermore, in view of the present results and other studies, $8,14,29,30$ it is apparent that stabilization from homoaromaticity and bicycloaromaticity is not possible in neutral or anionic hydrocarbons. The molecules' occupied and unoccupied orbitals are well separated energetically. Consequently, their interaction cannot be realized without forcing geometrical distortions that yield too much loss of bonding or increases in four-electron repulsive interactions. Thus, homoaromaticity is found only for a small class of carbonium ions in which stabilization occurs by mixing the empty p orbital with properly oriented, high-lying, occupied $\pi$ or $\sigma$ orbitals. Bicycloaromaticity, which is an enhanced form of homoaromaticity resulting from the presence of additional unsaturated bridges, is likely only relevant for the 7-norbornadienyl cation. Invocation of these effects outside of the restricted contexts described here should be viewed with great skepticism.

Acknowledgment is made to the donors of the Petroleum Research Fund, administered by the American Chemical Society, for support of this work.

(29) Grutzner, J. B. J. Am. Chem. Soc. 1976, 98, 6385.

(30) Kaufmann, E.; Mayr, H.; Chandrasekhar, J.; Schleyer, P. v. R. J. Am. Chem. Soc., following paper in this issue.

\title{
Elusiveness of Bishomoaromaticity in Anionic Systems: The Bicyclo[3.2.1]octa-3,6-dien-2-yl Anion
}

\author{
Elmar Kaufmann, Herbert Mayr,* Jayaraman Chandrasekhar, and \\ Paul von Ragué Schleyer
}

Contribution from the Institut für Organische Chemie der Friedrich-Alexander Universität Erlangen-Nürnberg, Henkestrasse 42, D-8520 Erlangen, Federal Republic of Germany. Received July 11, 1980

\begin{abstract}
The electronic structure of the bicyclo[3.2.1]octa-3,6-dien-2-yl anion (6), considered to be the prototype bishomoaromatic anion, was analyzed by semiempirical (MNDO) and ab initio (STO-3G) MO calculations. No evidence for homoaromatic stabilization (i.e., cyclic delocalization) was found. C-2-C-7 distances and Mulliken overlap populations between these carbons are almost identical in the $6 \pi$ anion 6 and the corresponding $4 \pi$ cation 7 . The calculated stabilization energy of anions 21 and 24 is similar to that of the alleged homoaromatic species 6 even though the orientation of the additional double bonds in 21 and 24 does not permit homoconjugative interaction with the allyl HOMO (eq 1,3,5). The experimentally observed stabilizing effect of the C-6-C.7 double bond in 6 is due to an inductive effect. In general, homoaromatic stabilization is not expected to be an important phenomenon in anions.
\end{abstract}

Applequist and Roberts recognized the unusual stability of the cyclobutenylium ion (1). ${ }^{1}$ The geometry of the small ring fa-

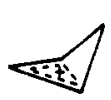

1

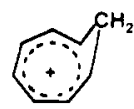

2

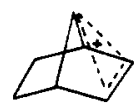

3

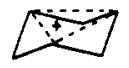

4 cilitates substantial 1,3- $\pi$-bonding; an ion (1), which resembles the aromatic cyclopropenyl cation electronically, was suggested to result. ${ }^{1}$ Winstein generalized this idea: the aromatic stabi-

(1) Applequist, D. E.; Roberts, J. D. J. Am. Chem. Soc. 1956, 78, 4012. lization of conjugated systems with $(4 n+2) \pi$-electrons may not be destroyed completely by the insertion of one or more intervening groups. ${ }^{2}$ This concept, "homoaromaticity", won rapid acceptance. ${ }^{3,4}$ Cations $1^{5}$ and $2^{6}$ (monohomoaromatic), $\mathbf{3}^{7}$ (bishomo-

(2) Winstein, S. J. Am. Chem. Soc. 1959, 81, 6524

(3) For reviews see: (a) Winstein, S. Q. Rev. Chem. Soc. 1969, 23, 141 ; Spec. Publ-Chem. Soc. 1967, No. 21, 5; (b) Carbonium Ions 1972, 3, Chapter 22. (c) Paquette, L. A. Angew. Chem., Int. Ed. Engl. 1978, 17, 106.

(d) Warner, P. M. Top. Nonbenzoid Aromatic Chem. 1976, 2.

(4) For theoretical treatments, see: (a) Goldstein, M. J. J. Am. Chem. Soc. 1967, 89, 6357. (b) Hehre, W. J. Ibid. 1972, 94, 8908; 1973, 95, 5807; 1974, 96, 5207. (c) Haddon, R. C. Ibid. 1975, 97, 3608. (d) Jorgensen, W. L. Ibid. 1976, 98, 6784. (e) Haddon, R. C. J. Org. Chem. 1979, 44, 3608. 
aromatic), and $4^{8}$ (trishomoaromatic) are well-established examples.

Chemists were stimulated to seek further manifestations of this phenomenon; it is common to encounter experimental results interpreted in such terms. ${ }^{3}$ The high water mark was reached with the elegant paper of Goldstein and Hoffmann, ${ }^{9}$ who analyzed four different topologies for $\pi$ interactions: pericyclic, spirocyclic, laticyclic, and longicyclic. This treatment included homoaromaticity and homoantiaromaticity as special cases within the pericyclic topology. The authors recognized that stabilizing interactions should be more important with charged species in which the HOMO-LUMO energy differences of the interacting fragments are smaller than in neutral alternatives.

More recently, an ebb is apparent: an increasing number of experimental and theoretical investigations indicate homoconjugative stabilization to be an overrated phenomenon. ${ }^{10}$ In particular, the remarkable conclusion of Houk, Paquette, et al. ${ }^{106}$ that "homoconjugative interactions between neutral closed-shell systems are destabilizing" is opposite to previous deductions about homoaromaticity. Experimental support for their thesis comes from heats of hydrogenation, photoelectron spectra, and X-ray crystal structures of potentially homoaromatic molecules such as cis-1,4,7-cyclononatriene, ${ }^{11 \mathrm{a}}$ triquinacen $\mathrm{e}^{1 \mathrm{lb}}$ and hexaquinacene. ${ }^{10 \mathrm{~d}}$ Bicyclo[2.1.0]pent-2-ene, ${ }^{11 \mathrm{c}-\mathrm{f}}$ barrelene, ${ }^{11 \mathrm{gh}}$ and spirenes ${ }^{11 \mathrm{k}-\mathrm{k}}$ provide additional examples of destabilizing interactions.

According to Winstein ${ }^{3 \mathrm{~b}}$ and to Goldstein and Hoffmann, stabilizing $\pi$ interactions should be observable in appropriately constituted anions as well as in cations. However, we have already demonstrated that the potentially homoaromatic cyclohexadienyl anion 5 does not show homoconjugative 1,5 -interaction. ${ }^{10 c, e} \mathrm{We}$

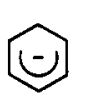

5

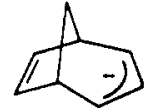

$6 a$

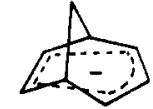

$6 \mathrm{~b}$

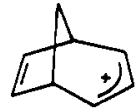

(5) Olah, G. A.; Staral, J. S.; Liang, G. J. Am. Chem. Soc. 1974, 96, 6233. Olah, G. A.; Staral, J. S.; Spear, R. J.; Liang, G. Ibid. 1975, 97, 5489.

(6) (a) Winstein, S.; Kaesz, H. D.; Kreiter, C. G.; Friedrich, E. C. J. Am Chem. Soc. 1965, 87, 3267. (b) Warner, P.; Harris, D. L.; Bradley, C. H.; Winstein, S. Tetrahedron Lett. 1970, 4013. (c) Winstein, S.: Kreiter, C. G.; Brauman, J. I. J. Am. Chem. Soc. 1966, 88, 2047. (d) Oth, J. F. M.; Smith D. M.; Prange, U.; Schröder, G. Angew. Chem., Int. Ed. Engl. 1973, 12, 327. (e) Paquette, L. A.; Broadhurst, M. J.; Warner, P.; Olah, G. A.; Liang, G. J. Am. Chem. Soc. 1973, 95, 3386

(7) (a) Winstein, S.; Shatavsky, M.; Norton, C.; Woodward, R. B. J. Am. Chem. Soc. 1955, 77, 4183. (b) Winstein, S.; Shatavsky, M. Ibid. 1956, 78, 592. (c) Winstein, S.; Hansen, R. L. Tetrahedron Lett. 1960, 25, 4. (d) Gassman, P. G.; Patton, D. S. J. Am. Chem. Soc. 1969, 91, 2160. (e) Lustgarten, R. K.; Brookhart, M.; Winstein, S.; Gassman, P. G.; Patton, D. S.; Richey H. G., Jr.; Nichols, J. D. Tetrahedron Lett. 1970, 1699.

(8) (a) Winstein, S.; Sonnenberg, J.; de Vries, L. J. Am. Chem. Soc. 1959 81, 6523. (b) Winstein, S.; Sonnenberg, J. Ibid. 1961, 83, 3235, 3244. (c) Winstein, S.; Friedrich, E. C.; Baker, R.; Lin, Y. Tetrahedron, Suppl. 1966, 8, Part 2, 621. (d) Masamune, S.; Sakai, M.; Kemp-Jones, A. V.; Nakashima, T. Can. J. Chem. 1974, 52, 855. (e) Coates, R. M.; Fretz, E. R. J. Am. Chem Soc. 1975, 97, 2538. (f) Olah, G. A.; Surya Prakash, G. K.; Rawdah, T. N. Whittaker, D.; Rees, J. C. Ibid. 1979, 101, 3935.

(9) Goldstein, M. J.; Hoffmann, R. J. Am. Chem. Soc. 1971, 93, 6193

(10) (a) Kao, J.; Radom, L. J. Am. Chem. Soc, 1978, 100, 760. (b) Houk K. N.; Gandour, R. W.; Strozier, R. W.; Rondan, N. G.; Paquette, L. A. Ibid. 1979, 101, 6797. (c) Olah, G. A.; Asensio, G.; Mayr, H.; Schleyer, P. v. R. Ibid. 1978, 100, 4347. (d) Christoph, G. G.; Muthard, J. L.; Paquette, L. A. Böhm, M. C.; Gleiter, R. Ibid. 1978, 100, 7782. (e) For further theoretical treatments of 5 see also: Burdon, J. Parsons, I. W. Avramides, E. J. J. Chem Soc., Perkin Trans. 1 1979, 1268. Birch, A. J.; Hinde, A. L.; Radom, L. J. Am. Chem. Soc. 1980, 102, 6430 and ref 4e. (f) Gordon, M. D.; Fukunaga T.; Simmons, H. E. Ibid. 1976, 98, 8401 .

(11) (a) Roth, W. R.; Bang, W. B.; Goebel, P.; Sass, R. L.; Turner, R. B.; Yü, A. P. J. Am. Chem. Soc. 1964, 86, 3178. (b) Stevens, E. D.; Kramer J. D.; Paquette, L. A. J. Org. Chem. 1976, 41, 2266. (c) Jorgensen, W. L. Borden, W. T. J. Am. Chem. Soc. 1973, 95, 6649. (d) Jorgensen, W. L. Ibid. 1975, 97, 3082. (e) Roth, W. R.; Klärner, F.-G.: Lennartz. H.-W. Chem. Ber 1980, 113, 1818. (f) Andrews, G. D.; Baldwin, J. E.; Gilbert, K. E. J. Org Chem. 1980, 45, 1523. (g) Haselbach, E.; Heilbronner, E.; Schröder, G. Helv. Chim. Acta 1971, 54, 153. (h) Turner, R. B. J. Am. Chem. Soc. 1964, 86, 3586. (i) Batich, C.; Heilbronner, E.; Rommel, E.; Semmelhack, M. F.; Foos, J. S. Ibid. 1974, 96, 7662. (j) Bischof, P.; Gleiter, R.; Dürr, H.; Ruge, B. Herbst, P. Chem. Ber. 1976, 109, 1412. (k) Hill, R. K.; Morton, G. H.; Rogers, D. W.; Choi, L. S., to be submitted for publication. suggested that, in general, monohomoaromaticity should be less significant in anions than in cations.

The bicyclo[3,2.1]octa-3,6-dien-2-yl anion (6), with $6 \pi$ electrons, is the most widely cited example of alleged anionic homoaromaticity; the experimental data seem to provide particularly convincing support of the predictions of qualitative $\pi$-MO theory. We have examined the degree of $\pi$ interaction in 6 and related anions by means of quantitative semiempirical and ab initio $\mathrm{MO}$ calculations. The corresponding potentially antiaromatic $4 \pi$ cationic system, 7, and its relatives have also been included in our study.

\section{Experimental Data}

The $\pi$-delocalized intermediate $6 \mathrm{~b}$ was first suggested by Brown and Occolowitz to account for the rapid base-catalyzed H/D exchange at C-4, $10^{4.5}$ times faster in 8 than in 9.12 Similarly, rapid $\mathrm{H} \cdot 4$ exchange was found for benzo[6,7]bicyclo[3.2.1]octa-2,6-diene e $^{13}$ and for bicyclo[3.2.2]nona-2,6-diene. ${ }^{14}$ The 2.3-ppm high-field shift of $\mathrm{H}-6$ and $\mathrm{H}-7$ in the ${ }^{1} \mathrm{H}$ NMR spectrum of 6 (relative to 8) was considered to be additional evidence for the homoaromatic delocalization of negative charge. $^{15}$<smiles>C1=CC(C2C3C=CCC2CC3)C2CC(C1)C2</smiles>

8<smiles>C1=CC(C2CCC2)C2CCC1C2</smiles>

9
This latter interpretation was questioned by Trimitsis and Tuncay ${ }^{16}$ They demonstrated that the base-catalyzed H-4 exchange is only 3.3 times faster in $\mathbf{1 0}$ than in 11, indicating the absence of homoconjugative<smiles>[PH2+]c1ccccc1</smiles><smiles>[PH2+]c1ccccc1</smiles><smiles>Pc1cccc(-c2ccccc2)c1</smiles>

stabilization in anion $12 .{ }^{16}$ On the other hand, $\mathrm{H}-6$ and $\mathrm{H}-7$ are $1.4 \mathrm{ppm}$ more shielded in 12 than in 10, approximately half the effect observed for the "homoaromatic" anion 6 . This suggested that effects other than homoconjugation might be responsible for the abnormal chemical shifts in 6.

Data for the corresponding cation (7) also do not provide conclusive evidence for interaction between the two $\pi$ systems. The solvolysis of the $p$-nitrobenzoate 14 was 235 times slower than that of $13 .{ }^{17}$ Diaz, Sakai,<smiles></smiles>

13<smiles>O[C@H]1C=CC2C=CC1C2</smiles>

14 and Winstein considered the magnitude of the rate reduction to be "in line with" the expected antiaromatic character of the dienyl cation 7. They pointed out, however, that the difference between the solvolysis rates might be due partially to the rate-retarding inductive effect of the second olefinic group in $\mathbf{1 4}$.

Cyclodelocalization can be analyzed more directly in free radicals than in anions and cations; the coefficients of the singly occupied MO's can be derived from the proton coupling constants in the ESR spectrum. ${ }^{18}$

(12) (a) Brown, J. M.; Occolowitz, J. L. Chem. Commun. 1965, 376. (b) Brown, J. M.; Occolowitz, J. L.; J. Chem. Soc. B 1968, 411. Brown, J. M.; Cain, E. N. J. Am. Chem. Soc. 1970, 92, 3821

(13) (a) Rosenthal, J. W.; Winstein, S. Tetrahedron Lett. 1970, 2683. (b) Brown, J. M.: Cain, E. N.; Mclvor, M. C. J. Chem. Soc. B 1971, 730. (14) (a) Moncur, M. V.; Grutzner, J. B. J. Am. Chem. Soc. 1973, 95, 6449. (b) Goldstein, M. J.; Natowsky, S. Ibid. 1973, 95, 6451

(15) (a) Brown, J. M. Chem. Commun. 1967, 638. (b) Winstein, S.; Ogliaruso, M.; Sakai, M.; Nicholson, J. M. J. Am. Chem. Soc. 1967, 89, 3656.

(16) (a) Trimitsis, G. B.; Tuncay, A. J. Am. Chem. Soc. 1975, 97, 7193; (b) 1976, 98, 1997.

(17) Diaz, A. F.; Sakai, M.; Wiństein, S. J. Am. Chem. Soc. 1970, 92 , 7477.

(18) (a) Sustmann, R.; Gellert, R. W. Chem. Ber. 1978, 111, 42. (b) Kawamura, T.; Takeichi, Y.; Hayashida, S.; Sakamoto, M.; Yonezawa, T. Bull. Chem. Soc. Jpn. 1978, 51, 3069. 
Sustmann and Gellert compared the ESR spectra of 15 and 16 and found

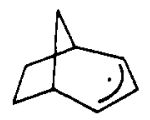

15

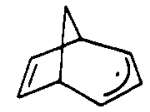

16 that the allylic hyperfine coupling constants with protons $\mathrm{H}-2, \mathrm{H}-3$, and $\mathrm{H}-4$ are not reduced by the extra double bond in $16 .^{18 \mathrm{a}}$ Furthermore, protons H-6 and H-7 showed only very small couplings in the ESR spectra of both 15 and 16, thus excluding significant delocalization in 16. This conclusion was corroborated by INDO calculations. ${ }^{18 a}$ In addition, Sustmann and Gellert reported that INDO calculations on anion 6 using the optimized geometry of radical 16 did not display homoconjugative interactions. To account for the experimentally observed stabilization of 6, the authors suggested a distortion of the bicyclic framework in the anion.

\section{Discussion}

Systems Examined. Our analysis is based on a comparison of the geometric, electronic, and energetic properties of the $6 \pi$ anion 6 and the $4 \pi$ cation 7 with the partially saturated ions 17 and 18 .

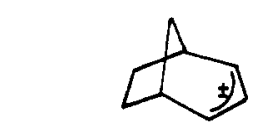

Cations

Anions

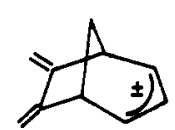

19

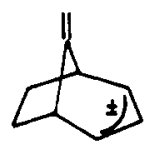

22
In addition, ions 19 and 21 , derived from the triene $\mathbf{2 0}$, and ions 22 and 24 , formed from 23 , were studied. The exocyclic double bonds are arranged in these systems so that orbital symmetry enforces a different interaction pattern than in 6 and 7 (Figure 1).

$\psi_{2}$ of the allyl fragment is antisymmetric (Figure 1) and may interact with $\pi^{*}$ in 6 and 7 or with the antisymmetric orbital, $\pi_{2}$, of the butadiene fragment in 19 and 21. $\psi_{2}$ cannot interact with the $\pi$ or $\pi^{*}$ orbitals of the exocyclic double bond in 22 and 24 (Figure 1, right side). Therefore, stabilization of anion 6 and of cation 19 but no stabilization of either cation 22 or anion 24 may be expected from symmetry considerations.

Computational Details. MNDO ${ }^{19}$ and $a b$ initio $^{20 a}$ (with the minimal STO-3G basis set) ${ }^{21}$ procedures were used to evaluate the magnitude of these interactions. Complete geometry optimizations were carried out at the MNDO level; $C_{s}$ symmetry constraints were employed for the ions. ${ }^{22}$ These MNDO geometries were then used for the ab initio calculations with one change: all $\mathrm{C}-\mathrm{H}$ bond lengths were set at $1.09 \AA$ instead of the larger $M N D O$ values. In addition, we performed MINDO/ 3 calculations, ${ }^{23}$ also with complete geometry optimizations, and single-point $\mathrm{ab}$ initio calculations (STO-3G) using the MINDO/3 geometries. Since the results were almost identical (deviations of $\Delta E$ 's in eq 1-6 were less than $1 \mathrm{kcal} / \mathrm{mol}$ ), they will not be included in this paper. MINDO/ 3 has previously been demonstrated to reproduce geometries of potentially homoaromatic systems very well. ${ }^{4 d, e, 10 c}$ Therefore, we expected the semiempirical methods also to give reliable structures for the systems considered here. This assumption is supported by the agreement between the STO-3G stabilization energies based on semiempirical structures and the

(19) Dewar, M. J. S.; Thiel, W. J. Am. Chem. Soc. 1977, 99, 4899 (20) (a) Hehre, W. J.; Lathan, W. A.; Ditchfield, R.; Newton, M. D. Pople, J. A., Gaussian 70, QCPE Program No. 236, Indiana University, Bloomington, Indiana. (b) Jorgensen, W. L. Ibid. Program No. 340, Indiana University, Bloomington, Indiana.

(21) Hehre, W. J.; Stewart, R. F.; Pople, J. A. J. Chem. Phys. 1969, 51, 2657 .

(22) Complete optimization of 6 without symmetry restrictions at the MINDO/3 level showed the energy minimum to correspond to $C_{s}$ geometry: Grutzner, J. B.; Jorgensen, W. L., preceding paper in this issue.

(23) Bingham, R. C.; Dewar, M. J. S.; Lo, D. H. J. Am. Chem. Soc. 1975, 97,1285 experimental stability order of $\mathbf{6}$ and $\mathbf{1 8}$ as well as of 7 and $\mathbf{1 7}$.

Orbital drawings were carried out with Jorgensen's plotting program ${ }^{20 b}$ using the STO-3G wave functions.

Geometries. In homoaromatic ions like 1-4, geometrical distortions take place which increase interaction between the termini of the $\pi$ systems. ${ }^{4}$ Such distortions indicate the presence of homoconjugative interactions.

However, the calculated MNDO geometries of the ions included in Table I do not provide any evidence for homoaromaticity. The allylic bond lengths (C-2-C-3) remain virtually unchanged $(r=$ $1.395 \pm 0.001 \AA$ ) in anions $6,18,21$, and 24 in spite of the differing number and positions of additional double bonds. Similarly, almost identical allylic bond lengths are calculated for the various cations 7, 17, 19, and $22(r=1.406 \pm 0.002 \AA)$.

The presence of cyclic conjugation in 6 might be expected to lead to a reduction of $\mathrm{C}-2-\mathrm{C}-7$ distance relative to that in cation 7. However, the C-2-C-7 distance is only $0.003 \AA$ shorter in the $6 \pi$ system 6 than in the $4 \pi$ system 7 . Analogously the C-2-C-7 distances in the other cations are only insignificantly different from those in the corresponding anions. Homoaromatic interaction is thus indicated to be unimportant in these ions.

Wave Functions. If cyclic conjugation occurs in 6, the antisymmetric allyl HOMO must be stabilized by admixture of the C-6-C-7 $\pi^{*}$ fragment. However, the appropriate p-orbital coefficients on C-6 and C-7 are negligible in the HOMO. A plot of the STO-3G wave function (Figure 2) shows this clearly. Slight interaction between the two systems in the ion may, however, be recognized in the LUMO which is primarily localized at C-6 and C-7.

The nonbonding orbitals of ions 6,17 , and 18 are also shown in Figure 2. A comparison of the HOMO's of anions 6 and 18 with the LUMO's of cations $\mathbf{7}$ and $\mathbf{1 7}$ is revealing: they are virtually identical. The antisymmetric allyl $\pi$ orbitals in these systems thus remain essentially unaffected by the presence or absence of additional double bonds.

Charge Distribution and Bond Orders. The results of Mulliken population analyses with STO-3G wave functions are shown in Table II. The charges on the allylic carbons $\mathrm{C}-2$ and C-3 in 6 are not very different from those in the other anions 18,21 , and 24. The charge reduction in 6 relative to 18 is only 0.026 electrons. Similar effects are also found for the cations $7,17,19$, and 22 , in which the allylic carbons bear nearly identical charges.

The greater shielding of the protons on C-6 and C-7 in 6 compared to those in 8 observed in the ${ }^{1} \mathrm{H}$ NMR spectra ${ }^{15}$ is partially reflected by the calculated charge distribution. There is a net increase of 0.05 electrons on C-6 and C-7 in 6 relative to neutral 8. However, a similar charge redistribution is seen in ions 21 and 24 as well: carbons 6,7 , and 9 in 21 and carbons 8 and 9 in 24 bear 0.05 and 0.03 more electrons, respectively, relative to their neutral counterparts. The charge polarization in these systems appears to be relatively insensitive to the orientation of the additional double bonds. Thus, the increased shielding of H-6 and H-7 in 6 does not necessarily imply the presence of cyclic delocalization.

Comparisons of the calculated C-2-C-7 and C-2-C-8 overlap populations in the different ions do not indicate any special stabilizing interaction in 6 . On the contrary, the values are all small and negative and indicate weak antibonding interaction in all cases. In particular, the $\mathrm{C}-2-\mathrm{C}-7$ overlap population in 6 is nearly the same as that in the corresponding cation $7(-0.043$ vs. -0.041$)$.

Energies. The energetic impact of the C-6-C-7 double bond in the ions 6 and 7 can be assessed by eq 1 and 2; the reaction

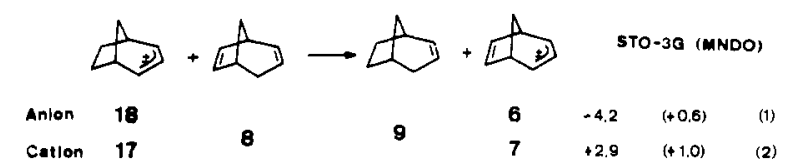

enthalpies are obtained from the data in Table III. Whereas MNDO predicts eq 1 and 2 to be almost thermoneutral, the $a b$ initio calculations indicate a stabilization $(4 \mathrm{kcal} / \mathrm{mol})$ of anion 6 relative to its saturated counterpart in agreement with the experimental data. Furthermore, the experimentally observed 


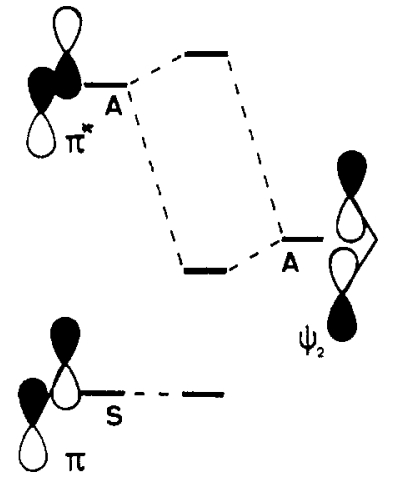

$\underline{6}, \underline{7}$

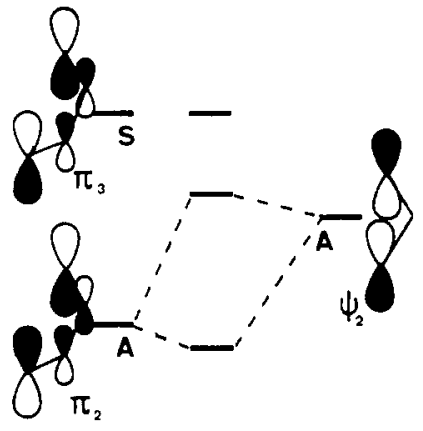

$\underline{19}, \underline{21}$

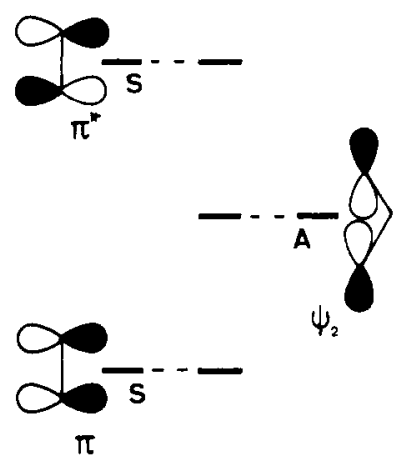

$\underline{22}, \underline{24}$

Figure 1. Symmetry-allowed interactions of the allylic $\pi_{2}$ orbital with ethylene fragments in different orientations.

Table I. MNDO Geometries of Hydrocarbons and Ions (Distances in A)

\begin{tabular}{|c|c|c|c|c|c|c|c|c|c|c|}
\hline & $X$ & species & $\begin{array}{c}\text { C-1-C-2 } \\
\text { (C-4-C-5) }\end{array}$ & $\begin{array}{c}C-2-C-3 \\
(C-3-C-4) \\
\end{array}$ & $\begin{array}{c}C-5-C-6 \\
(C-1-C-7) \\
\end{array}$ & $C-6-C-7$ & $\begin{array}{c}C-1-C-8 \\
(C-5-C-8) \\
\end{array}$ & $\mathrm{C}=\mathrm{CH}_{2}$ & $\begin{array}{c}C-2-C-7 \\
(C-4-C-6) \\
\end{array}$ & $\begin{array}{c}C-2-C-8 \\
(C-4-C-8) \\
\end{array}$ \\
\hline & $\begin{array}{l}+ \\
\mathrm{H} \\
-\end{array}$ & $\begin{array}{r}17 \\
9 \\
18\end{array}$ & $\begin{array}{l}1.511 \\
1.519 \\
1.556 \\
1.502\end{array}$ & $\begin{array}{l}1.406 \\
1.351 \\
1.514 \\
1.394\end{array}$ & $\begin{array}{l}1.573 \\
1.560 \\
1.561 \\
1.567\end{array}$ & $\begin{array}{l}1.549 \\
1.551 \\
\\
1.551\end{array}$ & $\begin{array}{l}1.563 \\
1.557 \\
1.557 \\
1.562\end{array}$ & & $\begin{array}{l}2.543 \\
2.529 \\
2.593 \\
2.547\end{array}$ & $\begin{array}{l}2.488 \\
2.481 \\
2.538 \\
2.484\end{array}$ \\
\hline & $\begin{array}{l}+ \\
\mathrm{H} \\
-\end{array}$ & $\begin{array}{l}7 \\
8 \\
6\end{array}$ & $\begin{array}{l}1.513 \\
1.520 \\
1.558\end{array}$ & $\begin{array}{l}1.407 \\
1.351 \\
1.517\end{array}$ & $\begin{array}{l}1.542 \\
1.531 \\
1.533\end{array}$ & $\begin{array}{l}1.352 \\
1.354\end{array}$ & $\begin{array}{l}1.573 \\
1.567 \\
1.565\end{array}$ & & $\begin{array}{l}2.483 \\
2.484 \\
2.543\end{array}$ & $\begin{array}{l}2.489 \\
2.486 \\
2.540\end{array}$ \\
\hline & $\begin{array}{l}+ \\
\mathrm{H} \\
-\end{array}$ & $\begin{array}{l}19 \\
20 \\
21\end{array}$ & $\begin{array}{l}1.513 \\
1.524 \\
1.561 \\
1.500\end{array}$ & $\begin{array}{l}1.404 \\
1.353 \\
1.507 \\
1.394\end{array}$ & $\begin{array}{l}1.543 \\
1.535 \\
1.533 \\
1.545\end{array}$ & $\begin{array}{l}1.487 \\
1.495 \\
\\
1.497\end{array}$ & $\begin{array}{l}1.565 \\
1.560 \\
1.558 \\
1.563\end{array}$ & $\begin{array}{l}1.347 \\
1.344 \\
1.342 \\
1.344\end{array}$ & $\begin{array}{l}2.470 \\
2.492 \\
2.551 \\
2.503\end{array}$ & $\begin{array}{l}2.497 \\
2.498 \\
2.547 \\
2.489\end{array}$ \\
\hline & $\begin{array}{l}+ \\
\mathrm{H} \\
-\end{array}$ & $\begin{array}{l}22 \\
23 \\
24\end{array}$ & $\begin{array}{l}1.512 \\
1.518 \\
1.559 \\
1.502\end{array}$ & $\begin{array}{l}1.405 \\
1.351 \\
1.512 \\
1.394\end{array}$ & $\begin{array}{l}1.573 \\
1.560 \\
1.562 \\
1.567\end{array}$ & $\begin{array}{l}1.548 \\
1.550\end{array}$ & $\begin{array}{l}1.533 \\
1.531 \\
1.529 \\
1.537\end{array}$ & $\begin{array}{l}1.340 \\
1.337 \\
\\
1.337\end{array}$ & $\begin{array}{l}2.549 \\
2.542 \\
2.609 \\
2.552\end{array}$ & $\begin{array}{l}2.439 \\
2.438 \\
2.498 \\
2.449\end{array}$ \\
\hline
\end{tabular}

Table II. Charges on Carbon and Overlap Populations (STO-3G) in Hydrocarbons and Ions

\begin{tabular}{|c|c|c|c|c|c|c|c|c|c|c|}
\hline & $\mathrm{X}$ & species & C-1 (C-5) & $C-2(C-4)$ & $C-3$ & C-6 (C-7) & C-8 & C-9 & $\begin{array}{l}\rho(2-7) \\
\rho(4-6) \\
\end{array}$ & $\begin{array}{l}\rho(2-8) \\
\rho(4-8)\end{array}$ \\
\hline & $\begin{array}{l}+ \\
\mathrm{H}\end{array}$ & $\begin{array}{r}17 \\
9 \\
18\end{array}$ & $\begin{array}{l}-0.052 \\
-0.037 \\
-0.026 \\
-0.024\end{array}$ & $\begin{array}{l}+0.134 \\
-0.068 \\
-0.112 \\
-0.255\end{array}$ & $\begin{array}{l}-0.099 \\
-0.065 \\
-0.065\end{array}$ & $\begin{array}{l}-0.100 \\
-0.107 \\
-0.103 \\
-0.104\end{array}$ & $\begin{array}{l}-0.091 \\
-0.103 \\
-0.105\end{array}$ & & $\begin{array}{l}-0.033 \\
-0.047 \\
-0.041 \\
-0.057\end{array}$ & $\begin{array}{l}-0.049 \\
-0.050 \\
-0.044 \\
-0.050\end{array}$ \\
\hline & $\begin{array}{l}+ \\
\mathrm{H}\end{array}$ & $\begin{array}{l}7 \\
8 \\
6\end{array}$ & $\begin{array}{l}-0.055 \\
-0.044 \\
-0.032 \\
-0.032\end{array}$ & $\begin{array}{l}+0.137 \\
-0.065 \\
-0.111 \\
-0.242\end{array}$ & $\begin{array}{l}-0.098 \\
-0.064 \\
-0.068\end{array}$ & $\begin{array}{l}-0.044 \\
-0.070 \\
-0.063 \\
-0.093\end{array}$ & $\begin{array}{l}-0.078 \\
-0.094 \\
-0.099\end{array}$ & & $\begin{array}{l}-0.041 \\
-0.048 \\
-0.044 \\
-0.043\end{array}$ & $\begin{array}{l}-0.049 \\
-0.050 \\
-0.045 \\
-0.053\end{array}$ \\
\hline & $\begin{array}{l}+ \\
\mathrm{H}\end{array}$ & $\begin{array}{l}19 \\
20 \\
21\end{array}$ & $\begin{array}{l}-0.056 \\
-0.045 \\
-0.034 \\
-0.034\end{array}$ & $\begin{array}{l}+0.133 \\
-0.065 \\
-0.111 \\
-0.247\end{array}$ & $\begin{array}{l}-0.100 \\
-0.063 \\
-0.061\end{array}$ & $\begin{array}{r}-0.004 \\
+0.004 \\
+0.008 \\
+0.019\end{array}$ & $\begin{array}{l}-0.087 \\
-0.102 \\
-0.105\end{array}$ & $\begin{array}{l}-0.094 \\
-0.136 \\
-0.137 \\
-0.174\end{array}$ & $\begin{array}{l}-0.035 \\
-0.047 \\
-0.044 \\
-0.051\end{array}$ & $\begin{array}{l}-0.049 \\
-0.048 \\
-0.043 \\
-0.050\end{array}$ \\
\hline & $\stackrel{+}{H}$ & $\begin{array}{l}22 \\
23 \\
24\end{array}$ & $\begin{array}{l}-0.059 \\
-0.048 \\
-0.037 \\
-0.036\end{array}$ & $\begin{array}{l}+0.134 \\
-0.064 \\
-0.110 \\
-0.251\end{array}$ & $\begin{array}{l}-0.098 \\
-0.064 \\
-0.060\end{array}$ & $\begin{array}{l}-0.098 \\
-0.106 \\
-0.102 \\
-0.104\end{array}$ & $\begin{array}{l}+0.012 \\
+0.020 \\
+0.037\end{array}$ & $\begin{array}{l}-0.104 \\
-0.153 \\
-0.199\end{array}$ & $\begin{array}{l}-0.034 \\
-0.045 \\
-0.039 \\
-0.056\end{array}$ & $\begin{array}{l}-0.055 \\
-0.052 \\
-0.048 \\
-0.050\end{array}$ \\
\hline
\end{tabular}




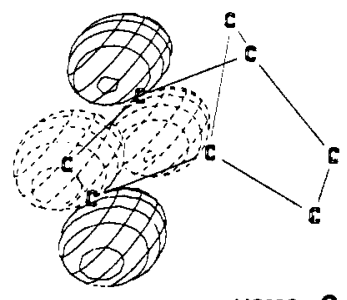

HOMO 6

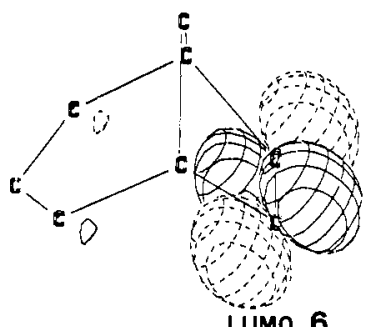

LUMO 6

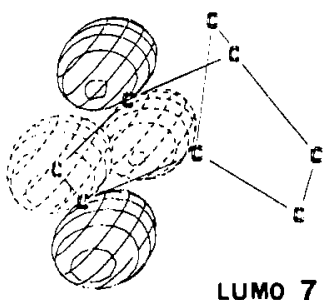

LUMO 7

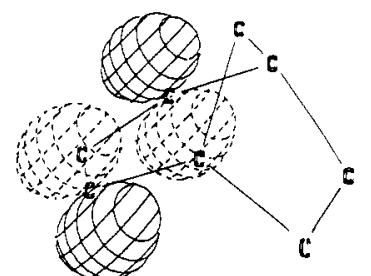

LUMO $\underline{17}$

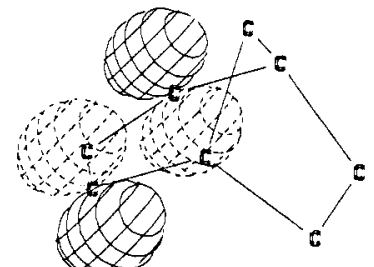

HоMо 18

Figure 2. Frontier orbitals (STO-3G) of some bicyclic anions and cations.

Table III. Calculated Heats of Formation $(\mathrm{kcal} / \mathrm{mol})$ and Total Energies (au) of Hydrocarbons and Ions Derived from Bicy clo [3.2.1] octane

\begin{tabular}{rrr}
\hline species & $\Delta H_{\mathrm{f}}{ }^{\circ}(\mathrm{MNDO})$ & $E_{\text {tot }}(\mathrm{STO}-3 \mathrm{G})$ \\
\hline 17 & 202.4 & -305.46172 \\
9 & 0.2 & -306.26070 \\
18 & 7.7 & -305.44542 \\
7 & 236.8 & -304.22557 \\
8 & 33.6 & -305.02916 \\
6 & 41.7 & -304.22064 \\
19 & 243.6 & -380.18377 \\
20 & 44.2 & -380.98186 \\
21 & 49.4 & -380.17930 \\
22 & 222.0 & -342.81740 \\
23 & 21.9 & -343.61629 \\
24 & 27.7 & -342.80867 \\
\hline
\end{tabular}

destabilization of cation 7 by the C-6-C-7 double bond is also reproduced by the STO-3G calculations. We thus regard the STO-3G energies to be more reliable.

How can the stabilization of 6 and the destabilization of 7 be explained, even though we do not find any evidence for $\pi$ interactions? Homoconjugative interactions may be present in $\mathbf{6}$ and 7 but are too small to be seen in the wave functions. Alternatively, the stabilization of 6 and the destabilization of 7 may be due to the inductive effect of the additional double bonds. The reaction enthalpies of eq 3-6 may be used to differentiate these two

$$
\text { anion }
$$

possibilities. In anions 21 and $\mathbf{2 4}$, the additional double bonds are orientated so that HOMO-LUMO interactions with the allylic fragment are symmetry inhibited. Nevertheless, the stabilization of 24 is similar in magnitude to that of 6 (eq 5); 21, with two exo double bonds, is stabilized to an even greater extent than 6 (eq 3 ). This demonstrates the operation of an inductive effect. Unlike 7 , cations 19 and 22 are not affected significantly by the extra double bonds (eq 2, 4, and 6). Homoconjugative interactions of small magnitude, destabilizing 7 and stabilizing 19 (see Figure 1), may be involved. C-C hyperconjugation, different for $\mathrm{sp}^{3}$ and $\mathrm{sp}^{2}$-hybridized carbons, may also contribute to the differences found. We prefer to defer detailed analysis of possible effects in alleged homoaromatic cations to the next paper in this series where systems better constituted for favorable interactions of $\pi$ fragments will be considered.

\section{Conclusions}

Since the bicyclo[3.2.1] octa-3,6-dien-2-yl anion (6) is clearly not a bishomoaromatic system, the same may well be true for other bicyclic anions which have similar structures as 6 . Anions 25, ${ }^{14 a}$<smiles>C1=CC2CCC1CC2</smiles>

25<smiles>C1=CC2CC(C1)c1ccccc12</smiles>

26<smiles>C1=CC2C=CC(CC2)N1</smiles>

27<smiles>O=C1OC(=O)C2CC1CCC2c1ccccc1</smiles>

$28^{\mathrm{Ph}}$
$26,{ }^{13} 27,{ }^{24}$ and $28,{ }^{25}$ for example, probably do not have the suggested delocalized structures. The $10 \pi$ electron system 29 , which has been demonstrated experimentally not to be a bishomoaromatic species, ${ }^{26}$ is another example in this series.

In parallel work, Grutzner and Jorgensen concluded that the experimentally observed stability of anion $\mathbf{3 0}$ is not due to long-

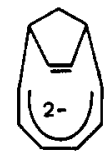

29

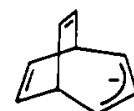

30

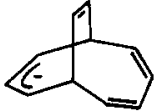

31 icyclic stabilization. ${ }^{22}$ The failure to observe longicyclic stabilization of $31^{27}$ experimentally is thus not an exception but is representative of the general rule that bicyclohomoaromaticity is not observable in anionic systems.

Qualitative MO theory that does not consider the magnitude of the overlap is obviously not sufficient for predicting stabilizations through interactions of $\pi$ fragments. It is likely that most of the systems that were thought to display aromatic stabilization on the basis of the symmetry properties of the fragment orbitals and the topology of their interactions ${ }^{9}$ do not do so because both the geometrical separation and the energy difference between the interacting ribbon orbitals are too large. In combination with

(24) Anastassiou, A. G.; Kasmai, H. J. Chem. Soc., Chem. Commun. 1975, 201

(25) Trimitsis, G. B.; Crowe, E. W.; Slomp, G.; Helle, T. L. J. Am. Chem. Soc. 1973, 95, 4333

(26) Paquette, L. A.; Kukla, M. J.; Ley, S. V.; Traynor, S. G. J. Am. Chem. Soc. 1977, 99, 4756

(27) Goldstein, M. J.; Nomura, Y.; Takeuchi, Y.; Tomoda, S. J. Am. Chem. Soc. 1978, 100, 4899. 
previous conclusions that homoaromaticity does not exist in neutral molecules ${ }^{10 \mathrm{~b}}$ and that monohomoaromaticity is not an important effect in anions, ${ }^{10 c}$ this work suggests that homoaromaticity may be restricted to cationic systems which can distort to increase the overlap of the interacting orbitals.
Acknowledgment. We thank R. Gleiter for discussion, W. L. Jorgensen and J. B. Grutzner for informing us of their work prior to publication, the Fonds der Chemischen Industrie for financial support, and the staff of the Regionales Rechenzentrum Erlangen for their cooperation.

\title{
$\mathrm{Na}^{+}$Complexes with Acyclic Polyethers. Stabilities, Enthalpies, and Entropies of Reaction in Acetonitrile and Pyridine. A Sodium-23 NMR Study
}

\author{
Jean Grandjean, ${ }^{1 \mathrm{a}}$ Pierre Laszlo, ${ }^{\text {1a }}$ Werner Offermann, ${ }^{1 \mathbf{a}}$ and Peter L. Rinaldi ${ }^{1 \mathrm{~b}}$ \\ Contribution from the Institut de Chimie Organique et de Biochimie, Universitê de Liège, \\ Sart-Tilman, 4000 Liège, Belgium. Received July 8, 1980
}

\begin{abstract}
Multinuclear NMR $\left({ }^{1} \mathrm{H},{ }^{13} \mathrm{C}\right.$, and $\left.{ }^{23} \mathrm{Na}\right)$ is applied to complex formation between $\mathrm{Na}^{+}$and a series of linear polyethers. The most interesting finding is the considerable difference in complexation enthalpies and entropies: while $\Delta H=-18 \pm 3$ $\mathrm{kJ} \cdot \mathrm{mol}^{-1}$ and $\Delta S=-11 \pm 3 \mathrm{~J} \cdot \mathrm{K}^{-1} \cdot \mathrm{mol}^{-1}$ for the sodium complex of 1,20-bis(o-(methylamido)phenoxy)-3,6,9,12,15,18-hexaoxaeicosane $(2 \cdot \mathrm{Na})$, the homologous ligand 1,11 -bis $(o$-(methylamido)phenoxy)-3,6,9-trioxaundecane $(1 \cdot \mathrm{Na})$ has $\Delta H=-66$ $\pm 10 \mathrm{~kJ} \cdot \mathrm{mol}^{-1}$ and $\Delta S=-185 \pm 45 \mathrm{~J} \cdot \mathrm{K}^{-1} \cdot \mathrm{mol}^{-1}$. This difference reflects pyridine solvent participation in $1 \cdot \mathrm{Na}$ (but not in 2. $\mathrm{Na}$ ) complex formation. When the weaker electron-donor solvent acetonitrile is used, solvent coordination to the cation is no longer significant for the $1 \cdot \mathrm{Na}$ complex.
\end{abstract}

\section{Introduction}

The preparation by Pedersen ${ }^{2}$ of cyclic polyethers which form strong complexes with metallic ions has ushered in a new era in chemistry. Crown ethers ${ }^{3}$ and cryptands ${ }^{4}$ are now routinely used in many industrial and chemical processes, for enhancing the solubility of salts in organic solvents and also for their cationbinding selectivity. ${ }^{5}$ Crown ethers are synthetic analogues of natural macrocycles such as those present in many antibiotic ionophores, which are known for their efficiency and selectivity in binding ions. Examples of acyclic ionophore antibiotics include monensin, nigericin, grisorixin, X-537 A (lasalocid), alborixin, and emericid. ${ }^{6}$ These biomolecules wrap themselves around the cation, in a manner very similar to the cyclic species. ${ }^{6}$ Acyclic synthetic analogues should behave likewise and thus should be useful additions to the available crown ethers and cryptands. Furthermore, acyclic oligoethers, called podands, 5,6 are obtained simply and cheaply; there is no need for high-dilution techniques or for template effects in their preparation. ${ }^{8}$ Vögtle's group has synthesized numerous such open-chain ligands. ${ }^{6}$

We have already shown the potential utility of ${ }^{23} \mathrm{Na}$ nuclear magnetic resonance for studying cation binding by organic and biological ionophores. 9 In a preliminary communication the complexing properties of ligand 1 toward the $\mathrm{Na}^{+}$cation were described. ${ }^{10}$ We report here results obtained also with the podands listed in Chart I.

We have selected these ligands, from a row of polyethers synthesized in the laboratory of Professor Vögtle in Bonn, because

(1) (a) Institut de Chimie Organique et de Biochimie, Université de Liège, Sart-Tilman par 4000 Liège, Belgium. (b) Department of Chemistry, Florida State University, Tallahassee, Florida 32306.

(2) Pedersen, C. J. J. Am. Chem. Soc. 1967, 89, 7017-7036.

(3) Christensen, J. J.; Eatough, D. J.; Izatt, R. M. Chem. Rev. 1974, 74, 351-384.

(4) Lehn, J. M. Struct. Bonding (Berlin) 1973, 16, 1-69. Acc. Chem. Res. 1978, 11, 49-57. Pure Appl. Chem. 1978, 50, 871-892.

(5) Schwind, R. A.; Gilligan, T. J.; Cussier, E. L. In "Synthetic Multidentate Macrocyclic Compounds"; Izatt, R. M. Christensen, J. J., Eds.; Academic Press: New York, 1978; pp 289-308.

(6) Vögtle, F.; Weber, E. Angew. Chem., Int. Ed. Engl. 1979, 18, 753-776.

(7) Vögtle, F. Chem.-Zig. 1971, 96, 396-403.

(8) De Sousa Healy, M.; Rest, A. J. Adv. Inorg. Chem. Radiochem. 1978, $21,1-40$.

(9) Laszlo, P. Angew. Chem., Int. Ed. Engl. 1978, 17, 254-266. Nachr. Chem., Tech. Lab. 1979, 27, 710-712. Bull. Magn. Reson. in press.

(10) Grandjean, J.; Laszlo, P.; Vögtle, F.; Sieger, H. Angew. Chem. 1978 90, 902-903. Angew. Chem., Int. Ed. Engl. 1978, 17, 856-857.
Chart I<smiles>[2H]c1ccccc1OCCOCCOCCOCCOCCOCCOCCO</smiles>

$1, n=1, \mathrm{R}=-\mathrm{NHCOCH}_{3}$

$2, n=3, \mathrm{R}=-\mathrm{NHCOCH}_{3}$

$3, n=1, \mathrm{R}=-\mathrm{CONHCH}_{3}$

4, $n=1, \mathrm{R}=-\mathrm{NH}-\mathrm{CO}$

$\mathrm{S}, n=1, \mathrm{R}=-\mathrm{NH}-\mathrm{CO}$
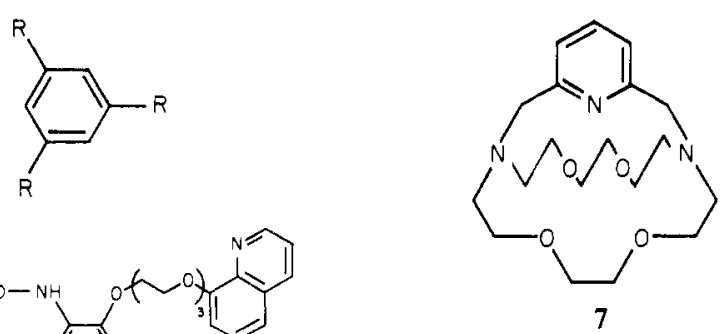

1, 1,11-bis(o-(methylamido)phenoxy)-3,6,9-trioxaundecane; 2 , 1,20-bis(o-(methylamido)phenoxy)-3,6,9,12,15,18-

hexaoxaeicosane; 3, 1,11-bis(o(methylamido)phenoxy)-3,6,9trioxaundecane; 4, 1,11-bis[o-((o-nitrophenyl)amido)phenoxy]-

3,6,9-trioxaundecane; 5, 1,11-bis[o-[ [0-(10-(o-nitrophenyl)-

$1,4,7,10$-tetraoxadecyl)phenyl] amido] phenoxy] $-3,6,9$ -

trioxaundecane; $6,1,3,5$-tris [ [o-(9-(8-quinolyloxy)-1,4,7-

trioxanonyl)phenyl] amido] benzene; 7 , pyrid inophane cryptand ((2.2.1)py $)^{13}$

they include pentaethers (compounds 1,3 , and 4 ), having also two nitrogen heteroatoms available for coordination to the cation. 